\title{
LA JUSTICIABILIDAD DE LOS DERECHOS SOCIALES. EL CASO DEL DERECHO AL HÁBITAT Y A LA VIVIENDA EN ECUADOR (2007-2017)*
}

\author{
THE JUSTICIABILITY OF SOCIAL RIGHTS. \\ HABITAT AND HOUSING RIGHTS IN THE CASE \\ OF ECUADOR (2007-2017)
}

LA JUSTICIABILITÉ DES DROITS SOCIAUX. LE CAS DES DROITS AU LOGEMENT ET L'HABITAT

EN EQUATEUR (2007-2017)

\author{
Francesco MANIGLIO** \\ Fernando CASADO GUTIÉRREZ ${ }^{* * *}$ \\ Gina CHÁveZ VALLEJO****
}

RESUMEN: La justiciabilidad de los derechos económicos, sociales, culturales y de la naturaleza representa el reto principal de la teoría y de las prác-

* Recibido el 6 de enero de 2020 y aceptado para su publicación el 25 marzo de 2020.

** Sociólogo y pedagogo. Doctor en Comunicación y Crítica de la Cultura por la Universidad de Sevilla; máster en Filosofía del Derecho por la Universidad Pablo de Olavide (España). Es investigador asociado al grupo Compolíticas de la Universidad de Sevilla y al Laboratorio de Estudios Críticos del Discurso (LABEC) de la Universidad de Brasilia.

*** Profesor titular principal en la Universidad Técnica de Manabí y profesor visitante en la Facultad Latinoamericana de Ciencias Sociales (FLACSO). Licenciado en Derecho por la Facultad de Granada (España); máster en Derechos Humanos y Democratización por la Inter-European University (EIUC) y doctor en Comunicación por la Universidad de la Laguna.

**** Doctora en Derecho, Ciencia Política y Criminología por la Universidad de Valencia (España); máster en Derecho Constitucional por la Universidad Andina Simón Bolívar (sede Ecuador); doctora en Jurisprudencia, y abogada de la República por la Universidad Central del Ecuador. Se desempeña como profesora titular principal del Instituto de Altos Estudios Nacionales (IAEN) y es miembro del Grupo de Trabajo de CLACSO, "Pensamiento Jurídico Crítico". Ha sido asesora del Ministerio de Defensa del Ecuador; del Consejo de Educación, Aseguramiento y Acreditación de la Calidad de la Educación Superior del Ecuador (CEAACES); de las asambleas constituyentes de 1998 y de 2008, y de otras instituciones públicas y privadas. 
ticas en torno a los derechos humanos en Latinoamérica, sobre todo en estos tiempos de crisis, restauración conservadora y regreso de la agenda neo liberal en la región. Sin embargo, en la última década el nuevo constitucionalismo latinoamericano ha experimentado un cambio radical respecto a la tradicional infravaloración de los derechos sociales y su exclusión como derechos subjetivos. El propósito del presente trabajo es analizar los procesos de justiciabilidad y las dimensiones de la exigibilidad del derecho al hábitat y a la vivienda en Ecuador (2007-2017), poniendo de relieve los limites históricos y las potencialidades políticas que el nuevo constitucionalismo latinoamericano ha representado en términos de justicia social.

Palabras clave: derechos humanos, DESC, nuevo constitucionalismo latinoamericano, Constitución de Montecristi, derecho a la vivienda.

ABSTRACT: The justiciability of the Economic, Social, Cultural and Nature Rights represent the main theoretical and practical challenge in the human rights field in Latin America, specially in the actual time of crisis, conservative restoriation and return of the neoliberal agenda in the region. However, in the last decade, the Latinamerican New Constitutionalism has undergone a drastic shift in relation to the traditional social rights understimation and their exclusion as subjetive rights. The present work purpose is analysis of the justiciability procedures and enforceability dimensions of the the habitat and housing rights in Ecuador (20072017), emphasizing the historic constrains and political potencialities that the Latinamerican New Constitutionalism has represented from a social justice perspective.

Keywords: human rights, ESCR, latinamerican new constitucionalism, Montecristi Constitution, housing right.

RÉSUMÉ: La justiciabilité des droits économiques, sociaux, culturels et de la nature représente le défi fondamental de la théorie et les pratiques relatives aux droits de l'homme en Amérique Latine, surtout en cette période de crise, restauration conservatrice et retour de l'agenda néolibéral dans la région. Cependant, durant la dernière décennie le Nouveau Constitutionalisme Latino-américain a connu un changement radical par rapport à la traditionnelle sous-estimation des droix sociaux et son valorisation comme droits subjectifs. L'objet du présent travail est d'analyser les procédures de justiciabilité et les dimensions de exigibilité du droit a l'habitat et au logement en Equateur (2007-2017), mis en évidence les limites historiques et les potentialités politiques que le Nouveau Constitutionalisme Latino-américain a donné en termes de justice sociale. 
Mots clés: droits humains, DESC, nouveau constitutionalisme latino-américain, Constitution de Montecristi, droit au logement.

SUMARIO: I. Introducción. II. La exigibilidad del derecho a la vivienda: entre normas emancipadoras y praxis regulatorias. III. Desde la especulación de la tierra a la Ley de Plusvalia. IV. Entre pasado y presente. Sobre las amenazas constitucionales $y$ la retórica de la justiciabilidad. V. Fuentes de consulta.

\section{INTRODUCCIÓN}

$\mathrm{H}$ istóricamente, las desigualdades sociales se han ido reforzando y legitimando a través de un discurso dominante sobre una supuesta incapacidad de alcanzar la exigibilidad de los derechos económicos, sociales y culturales. Esta "cultura estática y anestesiada" de ciertos derechos humanos se consolida en las ideologías sobre el Estado mínimo, limitado exclusivamente a garantizar la seguridad y defensa de nuestras sociedades.

No obstante, esta postura ha sido puesta en cuestión incluso desde los pensadores de la economía política clásica, como Adam Smith y David Ricardo, debido a la

...interrelación entre las supuestas obligaciones negativas del Estado, en especial en materia de garantía de la libertad de comercio, y una larga serie de obligaciones positivas, vinculadas con el mantenimiento de las instituciones políticas, judiciales, de seguridad y defensa, necesarias como condición del ejercicio de la libertad individual. ${ }^{2}$

En la actualidad, la defensa de los derechos y las libertades por parte de los neo republicanos no viene a significar la ausencia de oposición ${ }^{3} \mathrm{o}$ ausen-

1 Sánchez Rubio, David, "Crítica a una cultura estática y anestesiada de derechos humanos. Por una recuperación de las dimensiones constituyentes de la lucha por los derechos", Derechos y Libertades, núm. 33, 2015, pp. 99-133.

2 Abramovich, Víctor y Courtis, Christian, "Hacia la exigibilidad de los derechos económicos, sociales y culturales. Estándares internacionales y criterios de aplicación ante los tribunales locales”, en Abregú, Martín y Courtis, Christian (comps.), La aplicación de los tratados sobre derechos bumanos por los tribunales locales, Buenos Aires, Editores del Puerto, 1997, pp. 283-350.

3 Cfr. Hobbes, Thomas, Leviatán o la materia, forma y poder de una República eclesiástica y civil, México, FCE, 1992. 
cia de restricciones o de interferencias y coacción. ${ }^{4}$ En este sentido, el nuevo constitucionalismo latinoamericano apunta a promover una dimensión de la libertad como lucha en contra de la dominación y de la dependencia, ${ }^{5}$ y como reconocimiento ${ }^{6}$, ejercida como conjunto de derechos colectivos que poseen igualdad de jerarquía en su vigencia y garantía.

El nuevo constitucionalismo latinoamericano propone una inserción novedosa de los derechos sociales en el esquema constitucional, al reconocerle misma jerarquía e igual trato que a los demás derechos constitucionales. Esta situación deriva, a su vez, de un esfuerzo por consolidar una pulcra igualdad material, la que no sólo se extiende a los seres humanos existentes sino también, al menos en Ecuador y Bolivia, vincula a las personas con la naturaleza y con las demás generaciones. Esto conduce, además, al establecimiento de poderosos mecanismos de garantías orgánicas, jurisdiccionales y a nivel de interpretación. ${ }^{7}$

En la última década numerosos estudios han tenido como objeto el nuevo constitucionalismo latinoamericano, ${ }^{8}$ movidos por las propuestas radicalmente innovadoras que éste representa. Hablamos del giro multicultural de los derechos humanos en las regiones andinas, ${ }^{9}$ de los derechos étnico-territoriales ${ }^{10}$ y de la naturaleza. ${ }^{11}$

4 Cfr. Berlin, Isaiah, Cuatro ensayos sobre la libertad, Madrid, Alianza, 1998; Oppenheim, Felix, Political Concepts: A Reconstruction, University of Chicago Press, 1981.

5 Cfr. Pettit, Philip, "Liberalismo y republicanismo", en Martí, José Luis et al., Nuevas ideas republicanas: autogobierno y libertad, Barcelona, Paidós Ibérica, 2003, pp. 115-136.

6 Cfr. Camps, Victoria, Tolerancia, multiculturalidad, convivencia. Republicanismo contemporáneo, Bogotá, Siglo del Hombre Editores, 2002.

7 Aravena, Hugo, "Los derechos sociales en el nuevo constitucionalismo latinoamericano”, Revista de Derechos Fundamentales, núm. 13, 2015, p. 130.

8 Cfr. Schilling-Vacaflor, Almut, New Constitutionalism in Latin America: Promises and Practices, Londres, Routledge, 2016; Gibbs, Alun, "Theorizing Transformative Constitutional Change and the Experience of Latin American Constitutionalism", Law, Culture and the Humanities, 2017, disponible en: https:// doi.org/10.1177/1743872117711372, pp. 1-20.

9 Cfr. Seligmann, Linda y Fine-Dare, Kathleen, The Andean World, Londres, Routledge, 2018; Sieder, Rachel y Vivero, Anna, "Legalizing Indigenous Self-Determination: Autonomy and Buen Vivir in Latin America", The Journal of Latin American and Caribbean Anthropology, vol. 22, núm. 1, 2017, disponible en: https://doi.org/10.1111/jlca.12233, pp. 9-26.

10 Cfr. Kröger, Markus y Lalander, Rickard, "Ethno-Territorial Rights and the Resource Extraction Boom in Latin America: Do Constitutions Matter?", Third World Quarterly, vol. 37, núm. 4, 2016, disponible en: bttps:// doi.org/10.1080/01436597.2015.1127154, pp. 682-702.

11 Cfr. Carvalho, Alessandra et al., "A proteção jurídica da sustentabilidade ambiental 
Sin embargo, aún seguimos en una perspectiva positivista del derecho — anclada en la herencia colonial—, por la cual el cumplimiento (o no cumplimiento) de los procesos de justicia se establece ficticiamente en el orden de una posible yuxtaposición entre teoría (deber ser) y práctica (ser) de los derechos humanos. Desde nuestro punto de vista, debemos abandonar las relaciones ideal-típicas y abstractas de los derechos humanos y proyectarlos en el marco de un proyecto político que "no va a ser implementado porque exista la Constitución, sino porque persiste la voluntad del constituyente originario". ${ }^{12}$

En virtud de ello nos preguntamos, antes de todo, sobre las virtualidades emancipadoras del derecho a la vivienda en Ecuador; es decir, si los fundamentos sobre los que se sostiene, o para los que está construido el instrumento jurídico, son relevantes para integrar y poder garantizar las luchas sociales por un acceso igualitario a un hábitat, lo mismo que a una vivienda digna y adecuada.

En términos concretos, el avance sin precedentes en la positivización normativa y el reconocimiento de la justiciabilidad de los derechos sociales no siempre ha estado acompañado de prácticas jurídicas que los garanticen, dejando la mayoría de las veces en letra muerta estas prerrogativas, y con ello, la justicia social. La realidad nos obliga a dar un paso adelante y hacer una dura crítica al humanismo abstracto y las posturas iusnaturalistas que subyacen en ciertas concepciones teóricas de los derechos humanos, rescatando los procesos de justiciabilidad de los derechos humanos como parte de los conflictos (políticos) concretos que se dan en el campo económico, social, cultural y ecológico.

Cuando abandonamos el plano abstracto y nos comprometemos a tomar en consideración la relación que existe entre el derecho, ya como producto cultural, y las relaciones sociales que están en su base. Es decir, cuando bajamos del olimpo de la neutralidad y de la abstracción a la concreción de las situaciones sociales vividas por los individuos tanto en la soledad de su vida privada como en el marco de los grupos en los que se integran, no tenemos

no novo constitucionalismo latino-americano/The Legal Protection of Environmental Sustainability in the New Latin American Constitutionalism", Revista FSA (Centro Universitário Santo Agostinho), vol. 15, núm. 2, 2018, disponible en: https://doi.org/10.12819/2018.15.2.3, pp. 48-66.

12 Navas Alvear, Marco, "La justicia constitucional en el Ecuador, entre la política y el derecho”, Revista Jurídicas, vol. 10, núm. 2, 2013, pp. 81-208. 
otro remedio que relativizar la virtualidad existencial de tales acercamientos abstractos al fenómeno jurídico. ${ }^{13}$

El nuestro es, antes que nada, un posicionamiento político, porque decidimos abandonar las visiones ideal-normativistas del derecho que alaban el papel de las garantías y protección de individuos y colectivos en el plano abstracto. En cambio, nos focalizamos sobre los sistemas concretos de garantías políticas, económicas, sociales, culturales y jurídicas que refuerzan los resultados de las luchas sociales en términos de compromisos y deberes.

En el caso de Ecuador, nos referimos al amplio sistema de garantías constitucionales que se establece con la Constitución de 2008, ${ }^{14}$ especialmente en el caso del derecho al hábitat y a la vivienda. En primer lugar, estudiamos la efectividad de las garantías institucionales y jurisdiccionales (las garantías normativas) a través del análisis de las sentencias y casos que se han tratado en la Corte Constitucional de Ecuador en la materia. En segundo lugar, queremos describir cómo y de qué forma el Estado se atribuye como fin último proteger y garantizar la sustancialidad de los derechos a la vivienda y hábitat dignos. En términos metodológicos, en este trabajo hemos utilizado el análisis documental (AD) y de la información (AI) para sistematizar, estructurar y organizar las diversas posturas y normativas sobre el derecho a la vivienda desde una perspectiva histórica. Hablamos, generalmente, de textos normativos nacionales e internacionales, así como de las producciones doctrinarias que profundizan dichos textos normativos. Durante este proceso decidimos realizar una entrevista en profundidad al juez constitucional Patricio Pazmiño Freire, ${ }^{15,16}$ con el objetivo de complejizar el estudio del contexto jurídico — de los mecanismos y prácticas jurídicas- y de relacionar las informaciones concretas con las abstracciones y generalizaciones normativistas.

13 Herrera Flores, Joaquín, Los derechos bumanos como productos culturales. Crítica del humanismo abstracto, Madrid, Los Libros de la Catarata, 2005.

14 Éstas indican diversas acciones, como el habeas corpus, la acción de protección, el acceso a la información pública; el habeas data, la acción de incumplimiento, y la acción extraordinaria de protección.

15 Pazmiño Freire, Patricio, Los DESCA en América Latina. Algunas reflexiones sobre la actividad de la Corte Interamericana de Derechos Humanos, Francesco Maniglio y Fernando Casado, entrevistadores, 2018.

16 Actualmente es juez de la Corte Interamericana de Derechos Humanos. Fue presidente del Tribunal Constitucional del Ecuador (2007-2008) y presidente de la Corte Constitucional del Ecuador para el periodo de transición (2008-2012). 


\section{LA EXIGIBILIDAD DEL DERECHO A LA VIVIENDA: ENTRE NORMAS EMANCIPADORAS Y PRAXIS REGULATORIAS}

"Artículo 30. Las personas tienen derecho a un hábitat seguro y saludable, y a una vivienda adecuada y digna, con independencia de su situación social y económica". ${ }^{17}$ Así, las normas constitucionales reconocen amplios derechos y garantías en tema de vivienda y hábitat, sustentando el artículo 30 de la Constitución de la República de Ecuador (CRE) con el marco de los derechos del buen vivir. ${ }^{18}$ Un punto de partida radical es el reconocimiento de las desigualdades estructurales; de los procesos históricos para el acceso a la vivienda, el hábitat y la tierra como luchas para la dignidad humana. "La dignidad consiste en la obtención de un acceso igualitario a los bienes tanto materiales como inmateriales que se han ido consiguiendo en el constante proceso de humanización del ser humano". ${ }^{19}$ Entonces, el derecho a la vivienda se vincula al derecho a una vida digna, tal y como reconoce el artículo 66 de la Constitución: "El derecho a una vida digna, que asegure la salud, alimentación y nutrición, agua potable, vivienda, saneamiento ambiental, educación, trabajo, empleo, descanso y ocio, cultura física, vestido, seguridad social y otros servicios sociales necesarios". ${ }^{20}$

Las normas constitucionales de 2008 garantizan ${ }^{21}$ la protección y el acceso a una vivienda digna a los grupos de atención prioritaria, como los mayores, los jóvenes, las personas con discapacidad y las que han sido víctimas de desplazamientos. Este amplio sistema de garantías constitucionales establece la obligatoriedad de actuación de las funciones públicas en los procesos de justiciabilidad de los derechos. El derecho a la vivienda digna y hábitat se encuentra entre los llamados derechos del buen vivir o Sumak Kawsay, que son los que reciben una mayor atención al estar relacionados con el concepto filosófico de la cultura andina que influencia a la Constitución "en el marco de la interculturalidad y la convivencia armónica con la naturaleza". ${ }^{22}$

17 Constitución de la República del Ecuador, Quito, Asamblea Constituyente, 2008.

18 Cfr. Bonilla Maldonado, Daniel, "El constitucionalismo radical ambiental y la diversidad cultural en América Latina. Los derechos de la naturaleza y el buen vivir en Ecuador y Bolivia", Revista Derecho del Estado, núm. 42, 2019, disponible en: https://doi.org/10.18601/01229893. 442.01, pp. 3-23.

19 Herrera Flores, Joaquín, La reinvención de los derechos humanos, Sevilla, Atrapasueños, 2008, p. 28.

20 Constitución de la República del Ecuador, cit.

21 Ibidem, artículos 37, 39, 42 y 47.

22 Silva, Carolina, “¿Qué es el buen vivir en la Constitución?”, en Ávila, Ramiro (ed.), La 
La Constitución ecuatoriana es categórica cuando establece que "los derechos serán plenamente justiciables", al mismo tiempo que "inalienables, irrenunciables, indivisibles, interdependientes" y, en consecuencia, "de igual jerarquía”. ${ }^{23}$ La constituyente ecuatoriana dejó claro que no es aceptable ningún tipo de discriminación en los derechos, lo que se ve traducido en que la acción de protección para el amparo de los derechos tampoco contempla ningún tipo de diferenciación. En estos términos no cabe duda de que se han reforzado cabalmente las posibilidades y los espacios políticos para la justiciabilidad de los derechos económicos, sociales y culturales. Por lo tanto, vamos a analizar cómo se ha avanzado en los procesos concretos de las obligaciones estatales respecto al derecho a la vivienda: en el desarrollo de leyes y normas, de políticas públicas y de jurisprudencia específica.

\section{Las labores de la Corte Constitucional: desigualdades de acceso, protección en contra de los desalojos y garantía de la vida digna}

La Constitución de 2008 instituyó a la Corte Constitucional (CC) como el mayor organismo jurisdiccional a cargo de la interpretación de la propia carta constitucional, que sustituyó a su antecesor Tribunal Constitucional. No fue sólo un cambio nominal, sino sustancial, porque apuntaba a la construcción de un organismo que tuviera facultades jurisdiccionales como máximo intérprete de la Constitución. ${ }^{24} \mathrm{La}$ CC resuelve violaciones de derechos constitucionales y garantiza la vigencia material de los derechos. Esto deriva, en una gran cantidad de ocasiones, en el ordenamiento de las actuaciones del poder público y de los particulares, armonizándolos con los estándares nacionales e internacionales de protección de derechos. Como consecuencia, las decisiones de la CC devienen estratégicas en términos también culturales, porque contribuyen al fortalecimiento del ius commune latinoamericano, ${ }^{25} \mathrm{y}$ con ello al orden jurídico democrático nacional. ${ }^{26}$

En términos numéricos, la Corte, en los primeros nueve años de actividades, ha emitido 3,213 decisiones, entre sentencias y dictámenes, con una

Constitución del 2008 en el contexto andino. Análisis desde la doctrina y el derecho comparado, Quito, Ministerio de Justicia y Derechos Humanos, 2008, p. 125.

23 Constitución de la República del Ecuador, cit., artículo 11.

24 Pazmiño Freire, Patricio, op. cit.

25 Bogdandy, Armin et al., Transformative Constitutionalism in Latin America: The Emergence of a New Ius Commune, Oxford University Press, 2017.

26 Pazmiño Freire, Patricio, cit. 
media resolutiva en torno al $17 \%$ sobre el total de los casos presentados. Esta gran producción jurisprudencial, si de un lado refleja el enorme esfuerzo político durante una década para potenciar los mecanismos constitucionales del Estado, del otro reproduce y refleja las tradicionales desigualdades territoriales del país. Son las regiones urbanas, en efecto, las mayormente interesadas por las sentencias y dictámenes de la CC, mientras tanto, las regiones rurales se mantienen al margen de la justicia constitucional.

\section{DISTRIBUCIÓN DE SENTENCIAS/DICTÁMENES}

DE LA CORTE CONSTITUCIONAL ENTRE 2008-2018
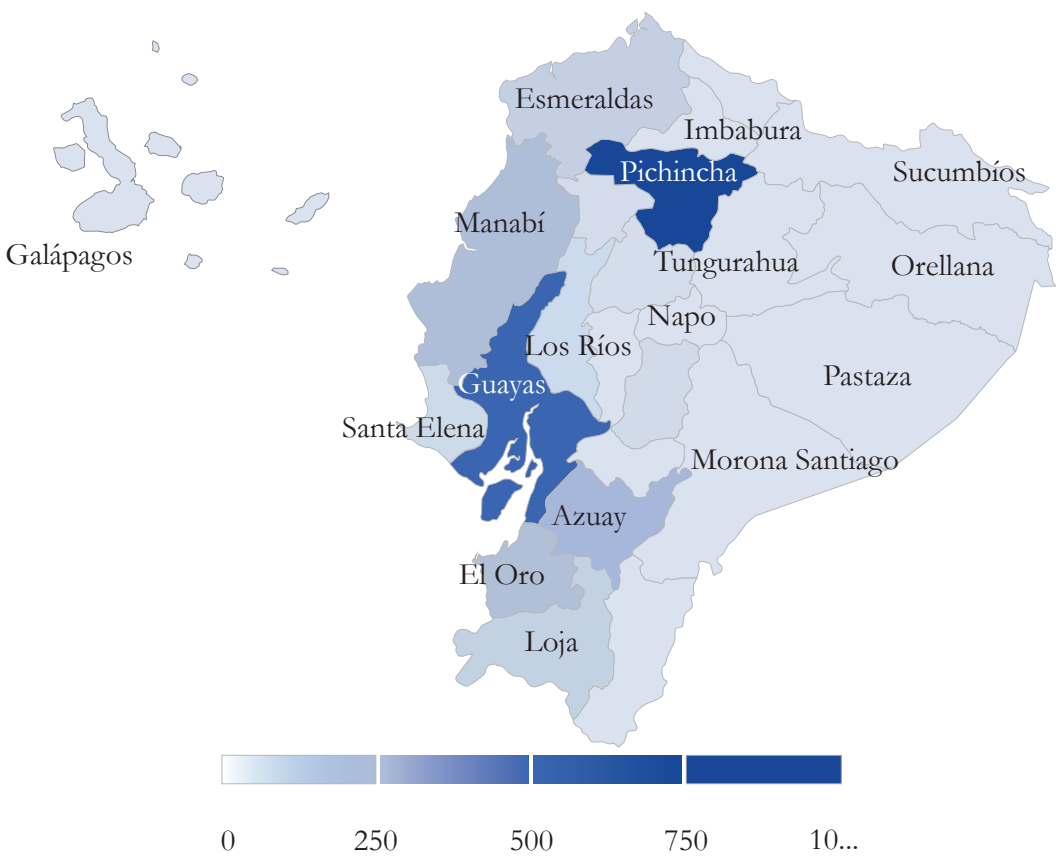

FUENTE: Estadísticas, Corte Constitucional Ecuador, 2018.

Esta polarización puede ser explicada sólo en parte por la alta proporción de la población urbana del Ecuador, que, como indica el Censo de Población y Vivienda del 2010, alcanza el 74.3\%. En el fondo persiste un acceso desigual a los mecanismos de justicia, lo que podría ser fácilmente relacionado con las divisiones socioculturales del país. En términos más 
específicos, debemos destacar las desigualdades socioeconómicas y la concentración de la pobreza que se mantiene alta en las zonas rurales.

\section{POBREZA POR NECESIDADES BÁSICAS (NBI) Y COEFICIENTE DE GINI POR PROVINCIA}

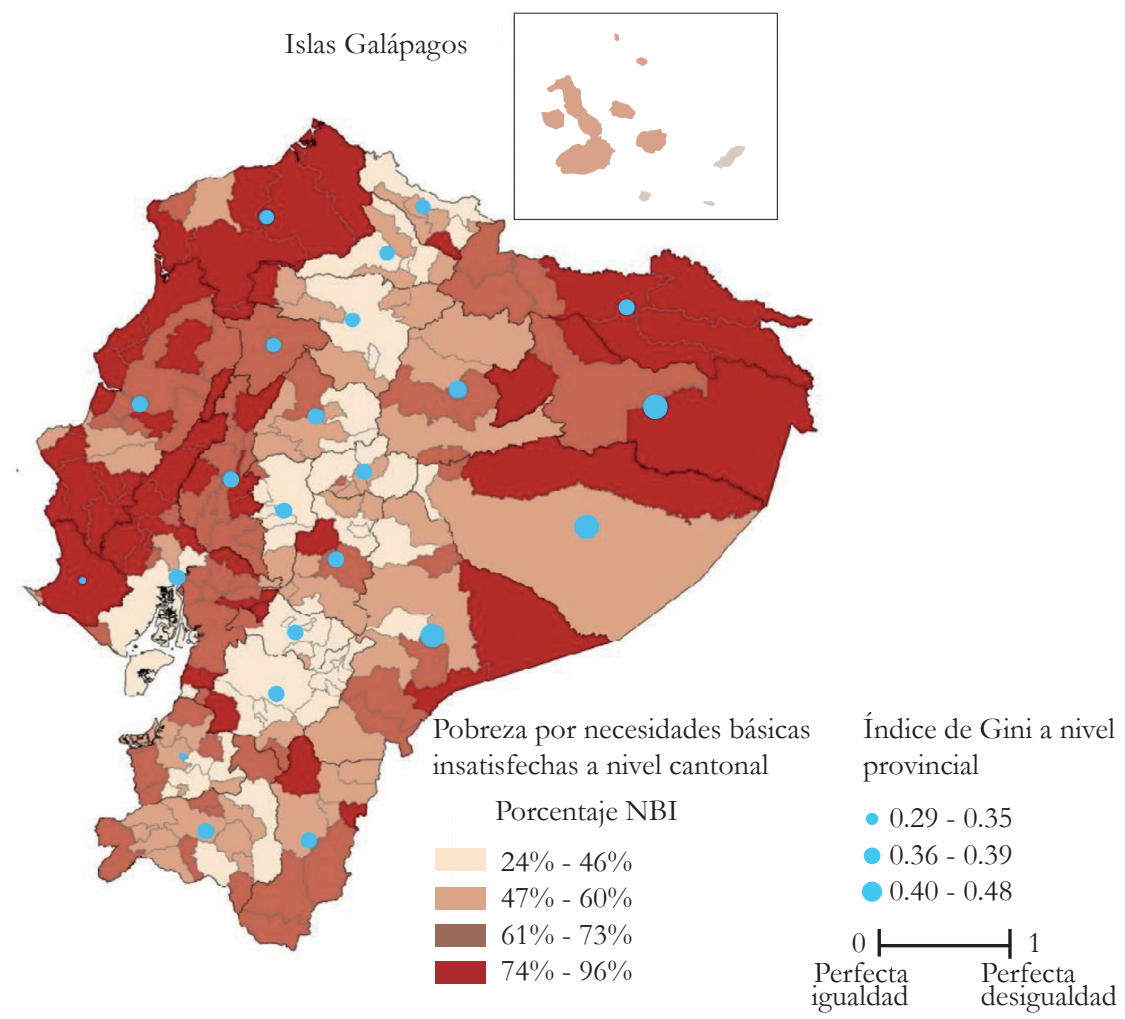

FUENTE: Censo de Población y Vivienda INEC, 2010. Elaboración MIDUVI, 2015.

De otro modo, específicamente a la temática del derecho a la vivienda y el hábitat, muchos de los conflictos en torno a las tierras y a la vivienda se constituyen, y también se resuelven, en los procesos de mercado informal e ilegal del "tráfico de tierras", de vivienda y de territorios. En estos puntos quizá se condensan las limitaciones de este trabajo — que avanzamos como hipótesis para futuras investigaciones-, al no haber un estudio paralelo sobre los pro- 
cesos específicos, como el "tráfico de tierras" y de viviendas, que intervienen en la reproducción de la injusticia respecto al derecho a la vivienda.

Las desigualdades de acceso y los procesos de "tráfico de tierras" y de viviendas explican, en parte, el hecho de que la CC sólo se ocupó directamente de la temática objeto de nuestro estudio en menos del 1\% del total de sus sentencias, constituyendo 17 los casos en que se ha demandado la tutela del artículo 30 (Derecho a la vivienda, derecho a la vivienda adecuada y digna, derecho al hábitat); del 37.7 (Derecho de los adultos mayores a vivienda digna), o/y del 47.6 (Derecho de las personas con discapacidad a una vivienda adecuada). Específicamente se han demandado tres acciones de inconstitucionalidad y 14 acciones extraordinarias de protección con base en los artículos citados, y se refieren, en su mayoría, a demandas desde los territorios urbanos.

Por otra parte, debemos contextualizar la relación entre las reivindicaciones materiales de derechos y el derecho procesal en dos dimensiones: una relacionada con el poder discrecional que mantienen los jueces de la CC sobre las decisiones definitivas y vinculantes respecto a los conflictos; otra relacionada con el mismo proceso de litis constitucional, que sigue reproduciendo la lógica ganador-perdedor, donde las disputas tienen como núcleo aspiraciones patrimoniales. La justicia constitucional se ve influenciada, de este modo, por intereses que exceden la defensa de derechos constitucionales y, evidentemente, esto tiene una fuerte repercusión sobre el alto número de causas que no pasan siquiera la fase de admisión o que terminan con la negación de las pretensiones del accionante.

Durante el proceso de análisis de las sentencias emitidas por la CC entre el 2010 y el 2017, en efecto, en no pocas ocasiones las demandas del accionante tienen que ver con pretensiones de naturaleza patrimonial. En la sentencia sobre el caso de la "Acción extraordinaria de protección presentada por Rosa Clementina Moreta Molina”, ${ }^{27}$ la CC se pronuncia por primera vez sobre el derecho a la vivienda ratificando su estatus de derecho del buen vivir o Sumak Kawsay. No obstante, frente a la garantía del derecho establecido en el artículo 37.7 de la CRE, de las personas adultas mayores a acceder a una vivienda que asegure su vida digna, la CC niega la acción extraordinaria de protección al identificar que la pretensión de las accionantes es de carácter legal y no constitucional.

Sobre este derecho hay que mencionar que tanto la sentencia del juez de primer nivel, como la de los jueces de la Corte, reconocen el derecho de las

27 Corte Constitucional del Ecuador, 0321-09-EP, 2010a. 
vencidas, a ser resarcidas en cuanto a su inversión, lo que garantiza que la Sra. Rosa Mareta Molina, de 70 años, pueda adquirir un nuevo inmueble que le permita vivir dignamente. ${ }^{28}$

En una segunda sentencia sobre el caso de la "Acción extraordinaria de protección en contra de la sentencia dictada por el Juez Décimo Tercero de lo Civil de Milagro", ${ }^{29}$ la Corte adelanta un examen mucho más minucioso de los derechos de propiedad y de vivienda digna relacionados con los artículos 66.26, 321, 30, 37.7, 39 y 47 de la CRE. Partiendo de un análisis sistemático de los derechos interrelacionados, la ratio decidendi acoge de manera expresa los estándares de "vivienda digna" contemplados en la Observación General No. 4 del Pacto Internacional de Derechos Económicos, Sociales y Culturales (PIDESC), que en relación con el artículo 375, orientan la implementación de políticas públicas de hábitat y vivienda. Por otro lado, la sentencia establece que el derecho a la vivienda "no implica la obligación del Estado de otorgar gratuitamente una vivienda a quien lo necesita". En el examen, la Corte advierte que el accionante confunde el derecho de propiedad con el derecho a la vivienda digna, lo que le lleva a concluir que la pretensión es meramente patrimonial.

Es desde este cuadro profundamente complejo e injusto - a nivel económico, social y cultural_-, entonces, que enfocamos la producción jurisprudencial de la CC desde 2010 hasta 2017 en el caso del derecho a la vivienda, antes que nada, para investigar la contradicción de los derechos económicos, sociales y culturales (DESC) con la producción de normas emancipadoras y la reproducción de la praxis regulatoria, y partiendo de la ratificación plena que hace la Constitución en el artículo 11 de la justiciabilidad de los DESC que consagra con claridad la obligación estatal frente a estos derechos. ${ }^{30}$

Sin lugar a dudas, este posicionamiento se refleja claramente en el desarrollo doctrinario de la CC sobre los DESC, en general, y el derecho a la vivienda, en particular, y también en los procesos de exigibilidad inmediata a través de medios jurisdiccionales frente a la progresividad de su desarrollo. Pensemos, por ejemplo, como la CC en 2012 resuelve de forma sustancial el caso de "Acción extraordinaria de protección presentada por Pablo Macario Pucha Poveda y María Eufemia Ronquillo", ${ }^{31}$ pronunciándose a favor de la incorporación de la doctrina del Comité de Derechos Económicos, Sociales

\footnotetext{
28 Ibidem, p. 7.

29 Corte Constitucional del Ecuador, 0343-09-EP, 2010b.

30 Pazmiño Freire, Patricio, op. cit.

31 Corte Constitucional del Ecuador, 1207-10-EP, 2012.
} 
y Culturales de las Naciones Unidas (2012), con la aplicación directa del PIDESC.

La Observación General No. 4 del Pacto Internacional de Derechos Económicos, Sociales y Culturales determina: “1. De conformidad con el párrafo 1 del artículo 11 del Pacto, los Estados Parte «reconocen el derecho de toda persona a un nivel de vida adecuado para sí y su familia, incluso, alimentación, vestido y vivienda adecuados, y a una mejora continua de las condiciones de existencia». Reconocido de este modo una vivienda adecuada, tiene una importancia fundamental para el disfrute de todos los derechos económicos sociales y culturales". En aquel sentido, se puede evidenciar que el señor Pablo Pucha y su esposa María Ronquillo detentan la edad de 81 y 77 años respectivamente; por tanto, se los considera adultos mayores, constituyendo un grupo de atención prioritaria por parte del Estado ecuatoriano. ${ }^{32}$

En este caso, en que se demandaron los derechos a la vivienda (artículo 30), a una vida digna a favor de personas adultas mayores (artículo 37.7) y tutela judicial efectiva (artículo 75), la Corte aceptó la acción extraordinaria de protección, por considerar que existió un exceso de funciones por parte de la Corte Nacional de Justicia, al casar la sentencia en su integralidad, y con ello, dejar sin efecto el reconocimiento y el acuerdo reparatorio de las partes. Esto se configura como un elemento objetivo de vulneración del derecho al hábitat y a la vivienda, así como vulneración al derecho de propiedad que comporta una obligación negativa de no poner en riesgo la propiedad y su uso. La Corte advierte:

En cuanto a la supuesta vulneración del derecho a la propiedad, se debe recordar que la Constitución de la República, en su artículo 321, reconoce entre las diversas formas de propiedad a la propiedad privada. En el caso sub judice la tutela del derecho a la propiedad comporta una obligación negativa asociada con el derecho a la propiedad del inmueble, en donde ninguna actividad realizada por una tercera persona puede afectar un bien inmueble perteneciente a otro sujeto, puesto que de producirse una afectación, aquello comportará una vulneración al derecho a la propiedad privada sobre ese bien inmueble. ${ }^{33}$

\footnotetext{
32 Ibidem, pp. 17 y 18

33 Ibidem, p. 19.
} 
La justiciabilidad de derecho a la vivienda y al hábitat se encuentra en el centro del debate de las motivaciones de esta acción extraordinaria de protección, en conexión con el derecho a la propiedad privada, e incluso la vida, como la CC argumentó en el presente caso:

En el presente caso, se puede determinar con claridad la existencia de una afectación al derecho a la vivienda, en detrimento del señor Pablo Pucha y su familia; este derecho se encuentra a su vez en estrecha relación con el derecho a la propiedad privada y su facultad para usar, gozar y disponer de la misma; en el caso sub judice, esta Corte puede evidenciar que por medio de la construcción del edificio contiguo, se atentó gravemente al patrimonio del señor Pablo Pucha, hasta colocar su vivienda en una situación de completa inseguridad para él y su familia, ya que mediante la construcción del edificio de propiedad actual de los sucesores del señor Héctor Lara se ha destruido el inmueble adjunto y se ha puesto en riesgo la propia vida de los habitantes del mismo. ${ }^{34}$

Sin embargo, fue con la sentencia sobre el caso de la "Acción extraordinaria de protección presentada por Luis Jorge Ramírez Enríquez" 35 que la CC avanzó en el desarrollo jurisprudencial y también en la atención mediática en torno al derecho a la vivienda. Con este dictamen la Corte defendió el derecho a la vivienda adecuada y digna dentro del marco del derecho al buen vivir y reconoció al Estado la función de actuar según dos conjuntos de obligaciones: un conjunto positivo, el establecimiento de políticas públicas, y un conjunto negativo, o sea, la abstención de conductas que puedan violar o vulnerar su efectivo goce. Es por este segundo conjunto que no sólo se aceptó la acción extraordinaria de protección, sino que también condenó al municipio del distrito metropolitano de Quito a la reparación integral de los daños:

Reparación integral: los jueces constitucionales se encuentran en la obligación de ser creativos al momento de determinar las medidas de reparación integral que dentro de cada caso puesto a su conocimiento deban ser establecidas, a fin de que la garantía jurisdiccional sea efectiva y cumpla su objetivo constitucional, evitando vincular únicamente a la reparación integral con una reparación reducida a lo económico, ya que su naturaleza es distinta. Por esta razón, dicha determinación deberá ser proporcional y

34 Ibidem, p. 20.

35 Corte Constitucional del Ecuador, 1773-11-EP, 2014. 
racional con relación a la función del tipo de violación, las circunstancias del caso, las consecuencias de los hechos y la afectación del proyecto de vida de la persona. ${ }^{36}$

Con esta sentencia se realizó un exhaustivo control de convencionalidad del derecho a la vivienda, al tomar en cuenta la Observación General No. 4 del Comité de Derechos Económicos, Sociales y Culturales y el artículo 11 del PIDESC, que se relaciona con la Constitución ecuatoriana de 2008. En consecuencia, se consideró el derecho a una vivienda digna de forma amplia, ligado "a un enfoque social, ambiental y ecológico", y a otros derechos constitucionales: "Como el derecho a transitar libremente, a escoger residencia, a la inviolabilidad de domicilio, a acceder a bienes y servicios públicos y privados de calidad, a vivir en un ambiente sano, ecológicamente equilibrado entre otros". 37

En la misma línea, la Corte, en el año 2016, reconoció la vulneración del artículo 37.7 (Derecho de los adultos mayores a vivienda digna) en el caso de la "Acción extraordinaria de protección contra la sentencia de 8 de julio de 2010, dictada por la Sala de lo Civil de la Corte Provincial de Justicia del Cañar", 38 que negó el otorgamiento del bono de la vivienda, vulnerando, de esta forma, el derecho constitucional a la vivienda de la demandante. Además, la Corte, con el objeto de tutelar los derechos de los grupos de atención prioritaria, emitió una sentencia interpretativa respecto al artículo 7o. del Reglamento para Operación del Sistema de Incentivos para la Vivienda (2015), para tutelar los casos referidos a situaciones de pobreza y pobreza extrema, dictando medidas de reparación integrales de la sentencia.

Cuando el postulante a un incentivo habitacional de vivienda urbano, rural y urbano marginal o amazónico, sea una persona que pertenece a cualquiera de las categorías de atención prioritaria establecidas en el artículo 35 de la Constitución de la República, cuyos ingresos estén por debajo de un salario básico unificado, sin importar que no cuenten a la fecha de postulación, con título de propiedad debidamente inscrito, deberá ser aceptada su postulación y atendida favorablemente, de manera inmediata. ${ }^{39}$

\footnotetext{
36 Ibidem, p. 49.

37 Ibidem, p. 32.

38 Corte Constitucional del Ecuador, 1180-10-EP, 2016.

39 Ibidem, p. 44.
} 
En 2017 la Corte, además, se pronunció de forma revolucionaria sobre la jerarquía de los DESC en el caso de la "Acción extraordinaria de protección, en contra de la sentencia dictada por la Tercera Sala de Garantías Penales de la Corte Provincial de Justicia de Pichincha (2012)", ${ }^{40}$ donde se ordenaba — por el principio de legalidad - derrocar el inmueble donde vivía el demandante. La Corte, en su sentencia, consideró que se estaría vulnerando el derecho a la vivienda adecuada y digna y los principios de igualdad y no discriminación, o sea, la dignidad humana, a causa de una supuesta garantía del principio de legalidad sobre el derecho a la vivienda.

El grado de afectación del principio de igualdad y no discriminación y el derecho a un hábitat seguro y saludable y a una vivienda adecuada y digna del accionante, de conformidad con el análisis precedente, se cataloga como intensa, correspondiéndole un valor de 4; el peso abstracto con un valor de 4, basado en relación a la mayor importancia en abstracto que se dé a la satisfacción del principio que se ubica en sentido contrario (principio de legalidad $v$ s. principio de igualdad y no discriminación y derecho a un hábitat seguro y saludable y una vivienda adecuada y digna); y, la seguridad de apreciaciones con un valor de 1 , pues versan sobre la afectación a los principios en colisión, las mismas que pueden tener un distinto grado de certeza — en el presente caso la afectación que la medida examinada, esto es, la demolición ordenada - proyecta sobre los principios relevantes que produce restricción al principio de igualdad y no discriminación, y al derecho a un hábitat seguro y saludable y una vivienda adecuada y digna. ${ }^{41}$

La Corte reforzó esta posición también en casos de expropiación o desalojo, como en la sentencia sobre el caso de la "Acción extraordinaria de protección presentada por Fabián Ramiro Gudiño Rodríguez". ${ }^{42}$ En este caso la Corte deniega al propietario del inmueble la acción extraordinaria de protección con base al artículo 82 (Derecho a la seguridad jurídica), en contra de la sentencia de acción de protección expedida por la Segunda Sala de lo Laboral, Niñez y Adolescencia de la Corte Provincial de Justicia del Guayas (516-09-2). Resumiendo, la mencionada Sala revocó la decisión judicial de la Intendencia General de Policía del Guayas — que mediante resolución había determinado el desalojo de 43 núcleos familiares-y, en consecuencia,

\footnotetext{
40 Corte Constitucional del Ecuador, 1301-12-EP, 2017 a.

41 Ibidem, pp. 19 y 20.

42 Corte Constitucional del Ecuador, 0310-10-EP, 2017b.
} 
concedió la acción de protección a los accionantes. En el mimo año la CC, sustancialmente, da razón a la Segunda Sala de lo Laboral, Niñez y Adolescencia de la Corte Provincial de Justicia del Guayas, por lo tanto, no observa que haya sido dictado en vulneración del derecho a la seguridad jurídica. Sin embargo, concretamente indica otro camino "necesario": el derecho a la vivienda.

Por lo tanto, la Corte Constitucional observa que en casos de asentamientos informales, las autoridades públicas deben adoptar medidas idóneas con el objetivo de evitar una vulneración constante de derechos, este deber de acción constituye una premisa para los jueces, quienes tienen la obligación de priorizar la dignidad humana en el ejercicio de la tutela judicial de los derechos constitucionales. ${ }^{43}$

En definitiva, la Corte denuncia cómo la orden de desalojo emitida por el intendente de policía violó el derecho a la vivienda digna y al hábitat a un núcleo de habitantes con escasos recursos económicos. Las autoridades hubieran tenido que "garantizar su estancia en el lugar donde se encontraban asentados", advierte la Corte, al contrario de disponer el desalojo. Se hubieran tenido que adoptar medidas necesarias para tutelar tales derechos, fundamentalmente — subraya — priorizando el derecho a la vida digna en las resoluciones de los conflictos en torno a la posesión de tierra.

\section{Las políticas públicas como garantía del derecho a la vivienda, al bábitaty a la tierra}

Algunas consecuencias políticas y culturales han surgido de este planteamiento constitucional en Ecuador. En primer lugar, se empezaron a cuestionar los orígenes de la pobreza; es decir, se insiste en el hecho de que es el fruto de relaciones conflictivas y de persistentes violaciones de los derechos humanos. ${ }^{44}$ En segundo lugar, se recuperó la idea de un Estado fuerte que,

\footnotetext{
43 Ibidem, p. 20.

44 Pensemos, por ejemplo, en cómo se ha simplificado el conflicto en el campo conceptual en torno a la pobreza, cuando los pueblos indígenas se han ubicado secularmente en los quintiles más pobres de las poblaciones de los países latinoamericanos, al punto de que la incidencia de la pobreza extrema en los indígenas es más del doble que la incidencia en el resto de la población. Cfr. Bello, Álvaro, Etnicidad y ciudadanía en América Latina, Santiago de Chile, CEPAL, 2000.
} 
con la Revolución Ciudadana (2007-2017), se caracterizó por 1) la (re)apropiación y nacionalización de recurso estratégicos; 2) la recuperación de la autonomía (relativa) del Estado y su capacidad de planificación, y 3) la fuerte inversión y extensión de políticas de bienestar social. Este proceso de transformación político-social marca el paso desde una esfera público-estatal, asentada en un régimen patrimonial, hacia una agenda social caracterizada por un mayor gasto público; una expansión de los servicios de salud, educación y protección social; mejoras en la calidad del mercado de trabajo, y reducción de la pobreza y desigualdad. ${ }^{45}$

Artículo 85. La formulación, ejecución, evaluación y control de las políticas públicas y servicios públicos que garanticen los derechos reconocidos por la Constitución, se regularán de acuerdo con las siguientes disposiciones: 1. Las políticas públicas y la prestación de bienes y servicios públicos se orientarán a hacer efectivos el buen vivir y todos los derechos, y se formularán a partir del principio de solidaridad. 2. Sin perjuicio de la prevalencia del interés general sobre el interés particular, cuando los efectos de la ejecución de las políticas públicas o prestación de bienes o servicios públicos vulneren o amenacen con vulnerar derechos constitucionales, la política o prestación deberá reformularse o se adoptarán medidas alternativas que concilien los derechos en conflicto. 3. El Estado garantizará la distribución equitativa y solidaria del presupuesto para la ejecución de las políticas públicas y la prestación de bienes y servicios públicos. ${ }^{46}$

En las políticas garantes de los derechos económicos y sociales, el Gobierno optó, desde sus inicios, por programas de bonos, subsidios y créditos dirigidos a mejorar el nivel de vida y la capacidad de consumo de sectores de estratos bajos y medio-bajos. Sostuvo una fuerte inversión en infraestructura vial nacional y el fortalecimiento de la cohesión social; en políticas para la eliminación de las dependencias energéticas; en fortalecimiento del sistema educativo inicial, primario, medio y superior; en el mejoramiento de servicios e instituciones públicas (salud, educación, seguridad social), y en programas de acceso a la vivienda digna, al hábitat y a la tierra, dirigidos a sectores populares y medios de la población. En términos legislativos, con los planes de desarrollo nacionales

45 Minteguiaga, Analía y Ubasart, Gemma, "Regímenes de bienestar y gobiernos «progresistas» en América Latina: los casos de Venezuela, Ecuador y Bolivia”, Política y Sociedad, vol. 52, núm. 3, 2015, p. 697.

46 Constitución de la República del Ecuador, cit. 
para el buen vivir, ${ }^{47}$ se establecen los objetivos y estrategias para garantizar el derecho a la vivienda en Ecuador. En particular, se establecen las políticas para "Garantizar el acceso a una vivienda adecuada, segura y digna" a través de diferentes lineamientos estratégicos:

\author{
PLAN NACIONAL PARA EL BUEN VIVIR (PNBV) \\ Y GARANTÍAS PARA LOS DERECHOS DE LA VIVIENDA
}

\title{
3.9. Garantizar el acceso a una vivienda adecuada, segura y digna
}

a) Promover el desarrollo de programas habitacionales integrales accesibles a personas con discapacidad y adecuados a las necesidades de los hogares y las condiciones climatológicas, ambientales y culturales, considerando la capacidad de acogida de los territorios.

b) Incentivar una oferta de vivienda social que cumpla con estándares de construcción y garantice la habitabilidad, la accesibilidad, la permanencia, la seguridad integral y el acceso a servicios básicos de los beneficiarios: transporte público, educación, salud, etcétera.

c) Generar instrumentos normativos y sus correspondientes mecanismos de aplicación para regular y controlar el alquiler de vivienda y permitir un acceso justo.

d) Promover la construcción de viviendas y equipamientos sustentables que optimicen el uso de recursos naturales y utilicen la generación de energía a través de sistemas alternativos.

e) Definir, normar, regular y controlar el cumplimiento de estándares de calidad para la construcción de viviendas y sus entornos, que garanticen la habitabilidad, la accesibilidad, la seguridad integral y el acceso a servicios básicos de los habitantes, como mecanismo para reducir el déficit cuantitativo y cualitativo de vivienda.

f) Generar estrategias de mejoramiento de viviendas deterioradas y en condiciones inadecuadas, riesgosas o de hacinamiento.

g) Promover la organización y responsabilidad familiar y comunitaria para garantizar su participación en la obtención de vivienda nueva o mejorada y en el mantenimiento oportuno y adecuado de las viviendas y sus entornos que evite el deterioro y los consecuentes riesgos.

47 Senplades, Plan Nacional para el Buen Vivir 2009-2013: construyendo un Estado plurinacional e intercultural, Quito, 2009; Senplades, Plan Nacional para el Buen Vivir 2013-2017, Quito, 2013. 


\subsection{Garantizar el acceso a una vivienda adecuada, segura y digna}

h) Generar programas que faciliten los procesos de legalización de la tenencia y propiedad del suelo y las viviendas, con principios de protección y seguridad.

i) Promover el acceso equitativo de la población a suelo para vivienda, normando, regulando y controlando el mercado de suelo para evitar la especulación.

FUENTE: PNBV 2013, 437.

Se intenta romper con el círculo vicioso financiación/especulación/imposibilidad de acceso a través de una serie de políticas enfocadas a la financiación pública con características sociales. Tanto el gobierno central como los gobiernos de los distritos metropolitanos autónomos y descentralizados han puesto en marcha varias estrategias con el objetivo de hacer efectivo el derecho a la vivienda, al hábitat y a la tierra.

Como podemos observar en el cuadro presentado un poco más adelante, hablamos, en su mayoría, de programas y planes para el acceso y la mejoría de la vivienda y del hábitat a través de las líneas de financiación (con el fortalecimiento de las instituciones de créditos populares) que hubieran tenido que garantizar el acceso para las clases con bajos y escasos recursos económicos. En términos generales; se obtuvieron enormes resultados. Pensemos en la inversión del Ministerio de Desarrollo Urbanístico y Vivienda (Miduvi) por casi mil millones de dólares, por un total de 246,382 intervenciones a través de varios programas de ayuda y financiación en el periodo 2007-2011.

Mientras tanto, el Banco del Instituto Ecuatoriano de Seguridad Social (BIESS), desde 2010, financió préstamos hipotecarios a cerca de 105,000 beneficiarios, con un monto total de 4,000 millones de dólares destinados a la adquisición de terrenos y viviendas. El BIESS también activó líneas crediticias para la construcción y remodelación de viviendas. Entre 2010 y 2015 el BIESS invirtió en estos programas cerca de 97 millones de dólares en 2,400 créditos mensuales. ${ }^{48}$

48 Miduvi, Informe Nacional del Ecuador para la Tercera Conferencia de las Naciones Unidas sobre Vivienda y Desarrollo Urbano Sostenible HABITAT III, Quito, Subsecretaría de Hábitat y Asentamientos Humanos, 2015. 


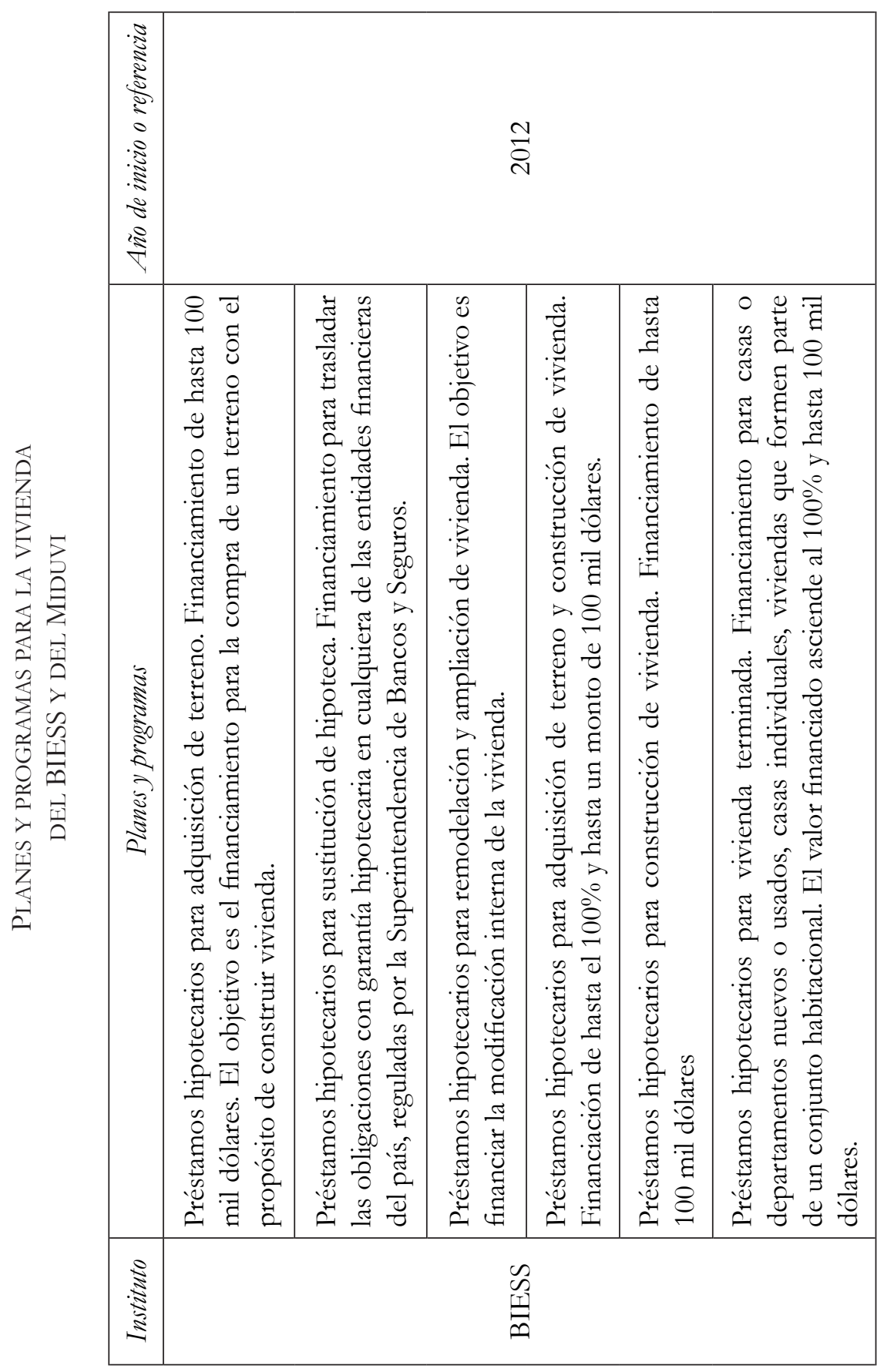




\begin{tabular}{|c|c|c|c|c|}
\hline 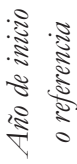 & \multicolumn{3}{|l|}{$\stackrel{\infty}{\stackrel{\infty}{\delta}}$} & 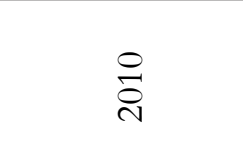 \\
\hline$\frac{3}{3}$ & \multicolumn{2}{|l|}{ 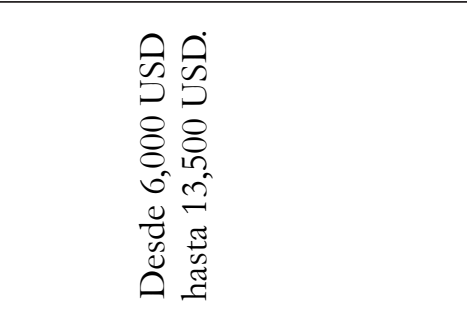 } & & 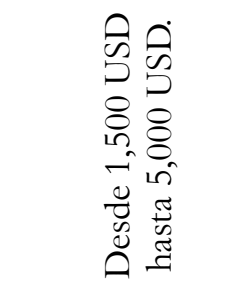 \\
\hline$\frac{2}{\sqrt[0]{2}}$ & 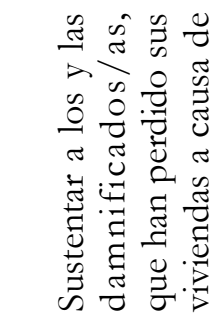 & & & 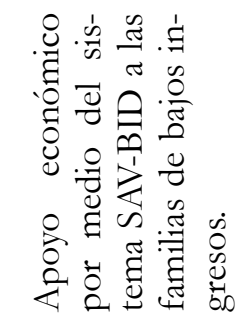 \\
\hline $\begin{array}{c}\overline{8} \\
5 \\
5 \\
5 \\
5\end{array}$ & 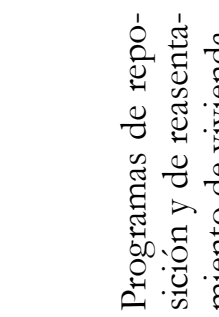 & & & 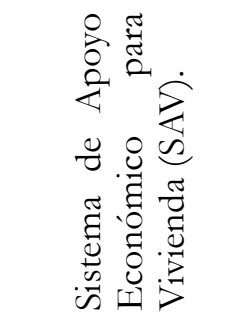 \\
\hline 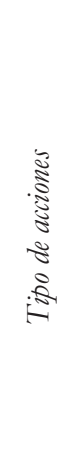 & 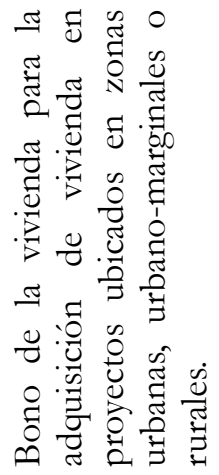 & 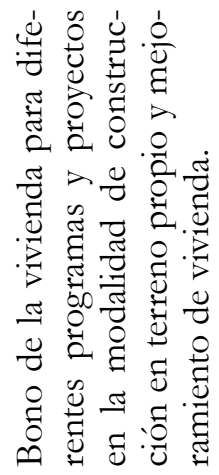 & 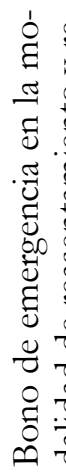 & 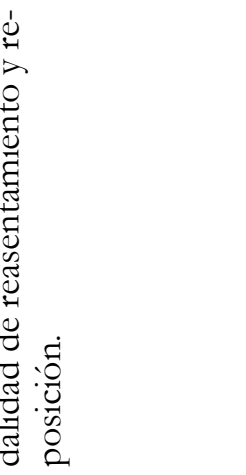 \\
\hline 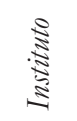 & & $\frac{\sqrt{Z}}{\stackrel{\Xi}{Z}}$ & & \\
\hline
\end{tabular}




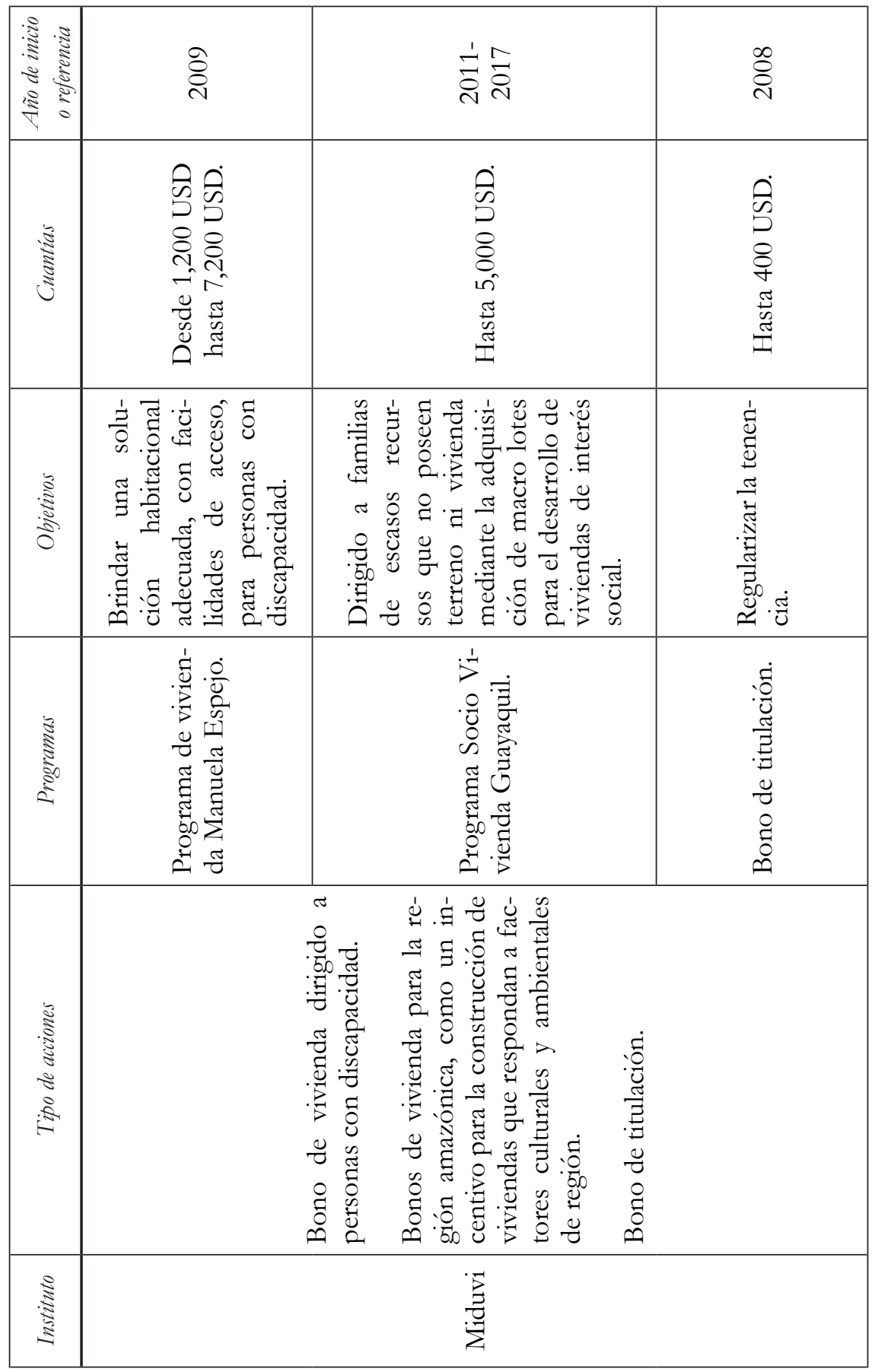


Sin embargo, estas financiaciones (del BIESS) tuvieron consecuencias contradictorias, porque acabaron por reforzar el acceso dual y desigual al mercado de vivienda. En efecto, sobre el total de monto financiado, la participación de los quintiles más bajos llegaba sólo al 3.5\% en 2012.49 Estos programas han acabado siendo disfrutados por los quintiles más altos, lo que fue reforzando un auge inmobiliario y unos efectos especulativos controvertidos y sin precedentes en Ecuador. ${ }^{50}$

\title{
III. DESDE LA ESPECULACIÓN DE LA TIERRA A LA LEY DE PLUSVALÍA
}

\begin{abstract}
El Comité recomienda al Estado parte que desarrolle planes de titulación que protejan la propiedad campesina sobre las tierras y establezca mecanismos de prevención de ventas forzadas en zonas rurales. El Comité recomienda al Estado parte que los procesos de reubicación de familias que habitan zonas de riesgo se lleven a cabo con arreglo a principios del derecho al debido proceso y se suministre plena información sobre las condiciones de la reubicación. El Comité recomienda al Estado parte que establezca mecanismos de monitoreo sobre los procesos de desalojo y de reubicación y su impacto en el disfrute del derecho a la vivienda, teniendo en cuenta las observaciones generales del Comité No. 4 y No. 7 sobre el derecho a una vivienda adecuada (párrafo 1 del artículo 11 del Pacto): los desalojos forzosos. ${ }^{51}$
\end{abstract}

El Comité de Derechos Económicos, Sociales y Culturales de las Naciones Unidas (2012) manifestó todas sus preocupaciones por algunas situaciones en el país. Entre estas especificó: 1) el tráfico de tierras y el proceso de pérdida de tierras por parte del campesinado a favor de empresas privadas, y 2) las condiciones precarias de viviendas en zonas de riesgo y/o por la falta de servicios. Recordemos que, desde la Constitución de 2008, con el Régimen de Competencias en la Organización Territorial del Estado, las políticas de

49 Derecho a la vivienda en Ecuador, Quito, Defensoría del Pueblo, 2013.

50 Cfr. Macías Rendón et al., “¿Existe evidencia de burbuja inmobiliaria en el Ecuador?”, Podium, núm. 28, 2015, disponible en: doi:10.31095/podium.2015.28.4, pp. 55-68; Vela, María, "Auge inmobiliario sin precedentes", Revista Gestión, núm. 213, 2011, pp. 14-30.

51 UN, Observaciones finales del Comité sobre el tercer informe periódico de Ecuador, E/C.12/ECU/CO/3 S, 2012, p. 4. 
educación, salud, seguridad social y vivienda son competencias directas del Estado central. Específicamente, la Constitución dispone, en el artículo 375, que es el Estado central el garante del derecho a la vivienda digna y al hábitat. Con la Constitución de 2008 se reconoce y se atribuye al Estado central la posibilidad de expropiar y controlar áreas, con el objetivo de poner freno a los efectos especulativos del mercado de tierras y vivienda y prevenir la creación de "burbujas inmobiliarias".

Artículo 376. Para hacer efectivo el derecho a la vivienda, al hábitat y a la conservación del ambiente, las municipalidades podrán expropiar, reservar y controlar áreas para el desarrollo futuro, de acuerdo con la ley. Se prohíbe la obtención de beneficios a partir de prácticas especulativas sobre el uso del suelo, en particular por el cambio de uso, de rústico a urbano o de público a privado. 52

De igual manera, se reconocen varias competencias también a los gobiernos de los distritos metropolitanos autónomos descentralizados para hacer efectivo el derecho a la vivienda, al hábitat y a la tierra. En particular, destacamos de los artículos 594 y 596 del Código Orgánico de Organización Territorial, Autonomía y Descentralización ${ }^{53}$ la posibilidad de expropiar la propiedad privada para garantizar la función social de la vivienda y el hábitat, lo mismo que resistir a las prácticas especulativas sobre las tierras. Estas atribuciones responden a la problemática histórica de los asentamientos urbanos y del tráfico de tierras que se vive en Ecuador. Los gobiernos descentralizados pueden, de esta forma, declarar la utilidad pública de tierras y viviendas con el objetivo de frenar la especulación.

Artículo 84. A fin de evitar el enriquecimiento injusto del titular, en concordancia con la prohibición constitucional de obtener beneficios a partir de prácticas especulativas sobre el uso de suelo, el justo precio para estos casos será determinado por la dirección de avalúos y catastros de cada gobierno municipal o metropolitano, con base en el valor del predio sin tomar en consideración las variaciones derivadas de uso actual del bien o su plusvalía. ${ }^{54}$

\footnotetext{
52 Constitución de la República del Ecuador, cit.

53 Código Orgánico Organización Territorial Autonomía Descentralización, T.4570-S/n.1 $-10-1516,2010$.

54 Idem.
} 
Lo que queremos señalar es que desde 2008 el Estado central y los gobiernos descentralizados tienen las prerrogativas y las funciones constitucionales para poder luchar en contra de las problemáticas coyunturales que se produjeron — en plena violación del derecho a la vivienda, al hábitat y a la tierra- por los mismos impactos de las políticas públicas para la vivienda y, sobre todo, por inversión pública en infraestructuras y servicios (20072017). Nos referimos al proceso conflictivo en torno a la "legalización o regularización de barrios" y a los procesos especulativos y el aumento de los precios de los terrenos y la vivienda. En efecto, desde 2010 y hasta 2012 la Defensoría del Pueblo de Ecuador ha registrado un gran incremento de denuncias presentadas en contra de empresas inmobiliarias, por un total de 291 denuncias, que se han presentado, en su mayoría, en las provincias de Pichincha y Guayas. ${ }^{55}$

Bajo este cuadro coyuntural y normativo, en 2016, la Asamblea Nacional de Ecuador aprobó la Ley Orgánica para Evitar la Especulación sobre el Valor de las Tierras y Fijación de Tributos, ${ }^{56}$ también conocida como Ley de Plusvalía, con el objetivo de frenar la violación sistémica de los derechos a la vivienda, al hábitat y a la tierra, y garantizar la progresividad de tales derechos según sus funciones. Es una ley, sin duda, radical, porque finalmente reconoce las desigualdades históricas en torno al acceso a la tierra y a la vivienda digna de Ecuador.

Históricamente, reducidos segmentos de la sociedad han obtenido ganancias extraordinarias ilegítimas provenientes de la especulación en la tenencia de bienes inmuebles. Asimismo, de forma generalizada, los propietarios de los bienes inmuebles han ido aprovechando el incremento de los precios de los bienes inmuebles, ocasionados entre otras cosas por la intervención del Estado a través de diferentes obras. ${ }^{57}$

Esta ley desarrolla mecanismos innovadores para dificultar la especulación y la acumulación financiera en el campo inmobiliario, al mismo tiempo que favorece la redistribución de las plusvalías del suelo, con políticas públicas en línea con los principios de progresividad del derecho a la vivienda digna y al hábitat, concentrándose en las zonas más afectadas históricamente. Así, con

\footnotetext{
55 Derecho a la vivienda en Ecuador, cit.

56 Ley Orgánica para Evitar la Especulación sobre el Valor de las Tierras y Fijación de Tributos, T.6659-SGJ-16-0027 §, 2016.

57 Idem.
} 
la Ley de Plusvalía se crea: a) un impuesto sobre el valor especulativo de la vivienda o del suelo (ganancia extraordinaria o plusvalía) por una porcentual fija del $75 \%$; catastros; c) se introducen medidas para enfrentar la pérdida de valor de un bien (minusvalía) afectado por obras públicas, y $d$ ) se descentralizan los recursos a los gobiernos autónomos, para la puesta en marcha de políticas públicas específicas para la garantía del derecho de vivienda digna y de hábitat (saneamiento, servicios básicos, etcétera).

\section{ENTRE PASADO Y PRESENTE.}

\section{SOBRE LAS AMENAZAS CONSTITUCIONALES \\ Y LA RETÓRICA DE LA JUSTICIABILIDAD}

De los 20 procesos constituyentes ocurridos desde el inicio de la República hasta la fecha, sólo tres podrían considerarse de ruptura en la perpetuación de las formas de dominio del derecho. Nos referimos a 1) la Asamblea Constituyente de 1830, que instaura la República, terminando formalmente la época del colonialismo español; 2) la Asamblea Constituyente de 1929, ${ }^{59}$ que asume los principales postulados de la Revolución liberal iniciada por Eloy Alfaro a finales del siglo XIX y que contiene un impulso a la modernización del Estado mediante la instauración de la libertad de trabajo y de contratación, del derecho a la educación, a la reunión y asociación y al sufragio femenino, ${ }^{60}$

58 Significa que quien gana más de lo ordinario (valor del inmueble o suelo, más la tasa de interés del banco central y el equivalente a 24 salarios básicos) en la compraventa de un inmueble deberá contribuir con un impuesto del 75\% sobre su ganancia extraordinaria.

59 La Constitución de 1945 fue resultado de la Revolución del 28 de mayo de 1944, conocida como "La Gloriosa". Es considerada rupturista por el grado de estructuración técnica y por la pionera creación del Tribunal Supremo Electoral, el Tribunal Constitucional, la Contraloría General del Estado y la Superintendencia de Bancos. A nivel de derechos y garantías, instaura el habeas corpus, reconoce el derecho a la educación, cultura y trabajo. A nivel tributario, adecúa los impuestos a la capacidad económica del contribuyente, entre otros avances. La Constitución de 1945 duró un año, y aunque algunas instituciones constitucionales subsistieron, se puede decir que "La Gloriosa" fue una revolución trunca.

60 Es importante anotar también que en 1861 se suprimió el requisito patrimonialista de que los votantes tuvieran una propiedad; en 1884 se eliminó el requisito rentista por el que los votantes debían tener una renta de tres mil pesos, y en 1978 se reconoció el derecho de voto de los analfabetos, entre los que se cuenta a un amplio número de indígenas y campesinos. La Constitución de 2008 reconoce, además, el voto facultativo para mayores de 16 años, para uniformados y para extranjeros, bajo requisitos específicos. 
la libertad de pensamiento, la obra pública, la institucionalidad pública y el laicismo, y 3) la Asamblea Constituyente de 2008, que concreta un proceso histórico a lo largo de dos décadas de conflicto y confrontación de importantes sectores sociales y políticos, históricamente al margen de la clase política tradicional y de las clases dominantes. ${ }^{61}$

La Constitución de Montecristi representó un proceso de transformación política y social, con el fortalecimiento del papel del Estado en aquellas disputas donde a lo largo de la historia había sido excluido. En el plano hegemónico cultural y social, a través del reconocimiento de las soberanías populares, de derechos económicos, sociales, culturales y ambientales. ${ }^{62}$ Asimismo, en el plano hegemónico material, a través de políticas públicas que son garantías y deben ser las prácticas de derecho de aquellas clases sociales que en Ecuador han sido oprimidas.

La voluntad de cambio frente a esta continuidad histórica explica el ascenso del gobierno de la Revolución Ciudadana y el fortalecimiento de los procesos constitucionales como espacio concreto de poder, de relación entre Estado y sociedad. El desarrollo normativo y político sobre los DESC entre 2008-2017 fue, sin duda, radical, y fue acompañado por procesos socioeconómicos (en términos de diminución de desigualdades) que marcaron logros históricos para el Ecuador.

El avance en reconocimiento, protección y justiciabilidad que algunas de las nuevas Constituciones latinoamericanas han implicado en materia de derechos sociales, especialmente en Venezuela, Bolivia y Ecuador, constituyen, a diferencia de otras Constituciones, un marco jurídico-político ideal para la creación de un modelo de Estado democrático redistributivo de la riqueza y, por tanto, tendiente a la creación de mayores niveles de igualdad social en sociedades, hasta nuestros días, totalmente inequitativas. ${ }^{63}$

61 Los movimientos indígenas de la década de los noventa revisten una importancia estratégica en la dimensión cultural del constitucionalismo de Ecuador; en la necesidad de procesos políticos radicales en contra de las desigualdades derivadas por el proceso histórico de subalternización. Cfr. Ortiz, Pablo, "20 años de movimiento indígena en el Ecuador: entre la protesta y la construcción de un Estado plurinacional”, en Betancur J., Ana Cecilia (ed.), Movimientos indígenas en América Latina. Resistencia y nuevos modelos de integración, IWGIA, 2011; Santos, B. de S. y Grijalva Jiménez, Agustín (eds.), Justicia indigena, plurinacionalidad e interculturalidad en Ecuador, Quito, Abya Yala, 2012.

62 Pazmiño Freire, Patricio, op. cit.

63 Fernández, Albert, Los derechos sociales en las nuevas Constituciones latinoamericanas, Valencia, Tirant lo Blanch, 2010. 
Por lo que concierne al derecho constitucional a la vivienda digna y al hábitat, el avance jurisprudencial debe ser leído a la luz de un cuadro contradictorio e injusto: entre desigualdades de acceso y reproducción históricas de divisiones territoriales (desigualdades estructurales). Hablamos del predominio — de matriz colonial — de la mentalidad del derecho privado y patrimonial, no sólo en el ámbito de la función pública, sino del ejercicio del derecho en términos culturales. Recordamos como en este proceso es el Estado el que debe asumir la responsabilidad política de romper con estas formas de reproducciones. El desarrollo progresivo del derecho como parte de los DESC deviene estratégico.

Finalmente, la Constitución de 2008 nace en el marco de procesos populares de cambio político en favor de aquellas clases sociales y grupos nacionales históricamente marginados. Empero, en la actualidad política de Ecuador (2019) los caminos constitucionales parecen de nuevo sufrir un duro cambio de ruta. El gobierno del presidente Lenin Moreno (2017), en efecto, debilitó enormemente el poder de la CC, decretando y llevando a cabo, en febrero de 2018, una consulta popular sin que la CC haya tenido la posibilidad de manifestarse sobre la constitucionalidad del proceso, según sus funciones. ${ }^{64} \mathrm{El}$ objetivo de esta consulta fue legitimar, a través del poder popular y mediático, varias funciones y privilegios típicos de un modelo de Estado corporativo. Privilegios que asientan un duro golpe a los procesos de justiciabilidad del derecho a la vivienda digna y al hábitat. En la misma consulta fue propuesta y votada la derogación de la Ley de Plusvalía, lo que supone la violación del principio de desarrollo progresivo del derecho a la vivienda digna, al hábitat y a la tierra.

La Constitución de Montecristi está bajo ataque, con riesgo de convertirse en papel mojado. La lucha en contra del Estado corporativo sigue representando un conflicto histórico de la sociedad ecuatoriana. Por eso los procesos constitucionales de Ecuador en 2019 estuvieron en una nueva inflexión, objeto de intensos conflictos políticos y económicos. Sin embargo, el poder igualador de las leyes generales y abstractas nunca va detener los conflictos en torno a la justicia de una sociedad fundada en la colonialidad, la jerarquía y los privilegios; entre pasado y presente.

\section{FUENTES DE CONSULTA}

Abramovich, Víctor y Courtis, Christian, "Hacia la exigibilidad de los derechos económicos, sociales y culturales. Estándares internacionales y

64 Constitución de la República del Ecuador, cit. 
criterios de aplicación ante los tribunales locales", en ABREGÚ, Martín y COURTIS, Christian (comps.), La aplicación de los tratados sobre derechos bumanos por los tribunales locales, Buenos Aires, Editores del Puerto, 1997.

ARAVENA, Hugo, "Los derechos sociales en el nuevo constitucionalismo latinoamericano", Revista de Derechos Fundamentales, núm. 13, 2015.

BeLlo, Álvaro, Etnicidad y ciudadanía en América Latina, Santiago de Chile, CEPAL, 2000.

BERLIN, Isaiah, Cuatro ensayos sobre la libertad, Madrid, Alianza, 1998.

Bogdandy, Armin et al., Transformative Constitutionalism in Latin America: The Emergence of a New Ius Commune, Oxford University Press, 2017.

Bonilla Maldonado, Daniel, "El constitucionalismo radical ambiental y la diversidad cultural en América Latina. Los derechos de la naturaleza y el buen vivir en Ecuador y Bolivia”, Revista Derecho del Estado, núm. 42, 2019, disponible en: https:// doi.org/10.18601/01229893.n42.01.

CAMPS, Victoria, Tolerancia, multiculturalidad, convivencia. Republicanismo contemporáneo, Bogotá, Siglo del Hombre Editores, 2002.

CARvalHo, Alessandra et al., "A proteção jurídica da sustentabilidade ambiental no novo constitucionalismo latino-americano/The Legal Protection of Environmental Sustainability in the New Latin American Constitutionalism", Revista FS A (Centro Universitário Santo Agostinho), vol. 15, núm. 2, 2018, disponible en: https:/ / doi.org/10.12819/2018.15.2.3.

Defensoría Del Pueblo, Derecho a la vivienda en Ecuador, Quito, 2013.

FERNÁNDEZ, Albert, Los derechos sociales en las nuevas Constituciones latinoamericanas, Valencia, Tirant lo Blanch, 2010.

GALINDO, Rocío, "Los derechos humanos fundamentados mediante la legitimación y la moral jurídica", Novum Jus: Revista Especializada en Sociología Jurídica y Política, vol. 10, núm. 1, 2016.

GIBBS, Alun, "Theorizing Transformative Constitutional Change and the Experience of Latin American Constitutionalism", Law, Culture and the Humanities, 2017, disponible en: https:/ / doi.org/10.1177/1743872117711372.

Gramsci, Antonio, Cuadernos de la cárcel, México, Ediciones Era, 1999.

HERRERA Flores, Joaquín, La reinvención de los derechos humanos, Sevilla, Atrapasueños, 2008.

HeRRERA Flores, Joaquín, Los derechos bumanos como productos culturales. Crítica del humanismo abstracto, Madrid, Los Libros de la Catarata, 2005. 
HoBBES, Thomas, Leviatán o la materia, forma y poder de una República eclesiástica y civil, México, FCE, 1992.

KRÖGER, Markus y LALANDER, Rickard, "Ethno-Territorial Rights and the Resource Extraction Boom in Latin America: Do Constitutions Matter?", Third World Quarterly, vol. 37, núm. 4, 2016, disponible en: https:/ / doi.org/1 $0.1080 / 01436597.2015 .1127154$.

MACÍAS RENDÓN et al., “¿Existe evidencia de burbuja inmobiliaria en el Ecuador?”, Podium, núm. 28, 2015, disponible en: doi:10.31095/podium.2015.28.4.

Miduvi, Informe Nacional del Ecuador para la Tercera Conferencia de las Naciones Unidas sobre Vivienda y Desarrollo Urbano Sostenible HABITAT III, Quito, Subsecretaría de Hábitat y Asentamientos Humanos, 2015.

Minteguiaga, Analía y Ubasart, Gemma, "Regímenes de bienestar y gobiernos «progresistas» en América Latina: los casos de Venezuela, Ecuador y Bolivia”, Política y Sociedad, vol. 52, núm. 3, 2015.

Navas Alvear, Marco, "La justicia constitucional en el Ecuador, entre la política y el derecho", Revista Jurídicas, vol. 10, núm. 2, 2013.

Oppenheim, Felix, Political Concepts: A Reconstruction, University of Chicago Press, 1981.

ORTIZ, Pablo, "20 años de movimiento indígena en el Ecuador: entre la protesta y la construcción de un Estado plurinacional", en BETANCUR J., Ana Cecilia (ed.), Movimientos indígenas en América Latina. Resistencia y nuevos modelos de integración, IWGIA, 2011.

PAZMIÑo FreIRE, Patricio, Los DESCA en América Latina. Algunas reflexiones sobre la actividad de la Corte Interamericana de Derechos Humanos, Francesco Maniglio y Fernando Casado, entrevistadores, 2018.

PetTIT, Philip, "Liberalismo y republicanismo", en MARTí, José Luis et al., Nuevas ideas republicanas: autogobierno y libertad, Barcelona, Paidós Ibérica, 2003.

SÁNCHEZ RuBIO, David, "Crítica a una cultura estática y anestesiada de derechos humanos. Por una recuperación de las dimensiones constituyentes de la lucha por los derechos", Derechos y Libertades, núm. 33, 2015.

SANTOS, B. de S. y GRIJALVA JimÉNEZ, Agustín (eds.), Justicia indigena, plurinacionalidad e interculturalidad en Ecuador, Quito, Abya Yala, 2012.

SCHILling-VACAFlor, Almut, New Constitutionalism in Latin America: Promises and Practices, Londres, Routledge, 2016.

Seligmann, Linda y FInE-DARE, Kathleen, The Andean World, Londres, Routledge, 2018. 
SiEDER, Rachel y ViVERO, Anna, "Legalizing Indigenous Self-Determination: Autonomy and Buen Vivir in Latin America", The Journal of Latin American and Caribbean Anthropology, vol. 22, núm. 1, 2017, disponible en: bttps:// doi.org/10.1111/jlca.12233.

SILVA, Carolina, “¿Qué es el buen vivir en la Constitución?”, en ÁvILA, Ramiro (ed.), La Constitución del 2008 en el contexto andino. Análisis desde la doctrina y el derecho comparado, Quito, Ministerio de Justicia y Derechos Humanos, 2008.

UN, Observaciones finales del Comité sobre el tercer informe periódico de Ecuador, E/C.12/ECU/CO/3 S, 2012.

VELA, María, "Auge inmobiliario sin precedentes”, Revista Gestión, núm. 213, 2011. 